\title{
? challenges
}

an Open Access Journal by MDPI

Affiliated Societies:

I inVIVO Planetary Health

DD Academic Open Access Publishing since 1996 


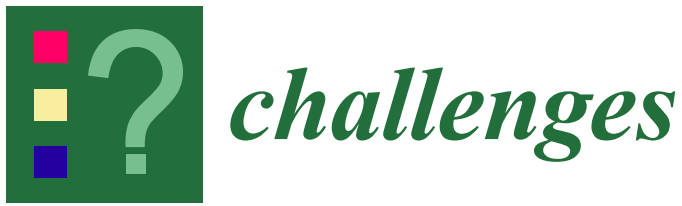

an Open Access Journal by MDPI

Editors-in-Chief

Dr. Palmiro Poltronieri

Prof. Dr. Susan L. Prescott

\begin{abstract}
Message from the Editors-in-Chief
Addressing scientific advancements and technological processes responding to societal needs are the new frontiers that humankind needs to face and cope with. Discovery and advances in basic research, synthetic biology, biochemistry, material science and biosystems engineering, are providing cutting edge progress and solutions. Scientists from multidiscipline fields are invited to discuss challenging science and research, and technology innovations in Challenges aimed towards solving current problematic issues.
\end{abstract}

\section{Author Benefits}

Open Access Unlimited and free access for readers

C No Copyright Constraints Retain copyright of your work and free use of your article

\section{\& Thorough Peer-Review}

$\square$ No Space Constraints, No Extra Space or Color Charges No restriction on the length of the papers, number of figures or colors

(1) Rapid Publication First decision provided to authors approximately 35 days after submission; acceptance to publication is undertaken in 3.9 days (median values for papers published in this journal in the first half of 2022) 


\section{Aims and Scope}

We welcome manuscripts that discuss any aspects of personal, environmental, economic and societal health, encouraging diverse perspectives from across many dimensions of the arts and the sciences, to explore novel solutions and new normative values. It is our hope that Challenges will facilitate collaborative vision and shared agendas that drive activity to link virtually every endeavor aimed at solving the interconnected challenges of our timelarge and small alike.

Research proposals; research plans; research ideas

Registered reports

Open problems, grand challenges, and collaborative efforts or competitive solving of these issues

Perspectives; ideas; solutions; discovery protocols

Prototypes; routes; procedures

Calls for, or description of, research collaborations or complementary support

Models; computation; theory and experiments

Open consultation, crowdsourcing in the scholarly context

Ideas or procedures aimed at accelerating research, development and production

Intellectual resources

Creative ideas and perspectives, including those that integrate the arts and sciences

\section{Editorial Office}

Challenges Editorial Office challenges@mdpi.com MDPI, St. Alban-Anlage 66 4052 Basel, Switzerland Tel: +41616837734 www.mdpi.com mdpi.com/journal/challenges 


\section{MDPI is a member of}

\section{CASPA}

The Association of Learned \& Profession Society Publishers

\section{Crossref \\ STM'}

Society

for Scholarly

Publishing
$|\mathbf{C}| \mathbf{O}|\mathbf{P}| \mathbf{E} \mid$

SPARC*

Europe

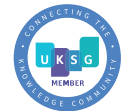

DOAJ

ORCID

\section{Follow}

f facebook.com/MDPIOpenAccessPublishing

3. twitter.com/MDPIOpenAccess

in linkedin.com/company/mdpi

(O) instagram.com/mdpiopenaccess

$\mathbf{6}^{\text {") }}$ weibo.com/mdpicn

Wechat:MDPI-China

\section{Subscribe}

blog.mdpi.com 